\title{
Factors influencing uptake of contraceptive implants in the immediate postpartum period among HIV infected and uninfected women at two Kenyan District Hospitals
}

Mufida M. Shabiby' ${ }^{1}$ Joseph G. Karanja ${ }^{1}$, Francis Odawa ${ }^{1}$, Rose Kosgei ${ }^{1}$, Minnie W. Kibore ${ }^{2 *}$, James N. Kiarie ${ }^{1}$ and John Kinuthia ${ }^{1,3}$

\begin{abstract}
Background: Family planning is a cost effective strategy for prevention of mother to child transmission of HIV and reduction of maternal/infant morbidity and mortality. Contraceptive implants are a safe, effective, long term and reversible family planning method whose use remains low in Kenya. We therefore set out to determine and compare the uptake, and factors influencing uptake of immediate postpartum contraceptive implants among HIV infected and uninfected women at two hospitals in Kenya.

Methods: This cross sectional study targeted postpartum mothers at two Kenyan district hospitals (one urban and one rural). All participants received general family planning and method specific (Implant) counseling followed by immediate insertion of contraceptive implants to those who consented. The data was analyzed by descriptive analysis, T-test, Chi square tests and logistic regression.
\end{abstract}

Results: One hundred eighty-five participants were enrolled (91 HIV positive and 94 HIV negative) with a mean age of 26 years. HIV positive mothers were significantly older (27.5 years) than their HIV negative counterparts (24.5 years), $P=0.001$. The two groups were comparable in education, employment, marital status and religious affiliation. Overall, the uptake of contraceptive implants in the immediate postpartum period was $50.3 \%$ and higher among HIV negative than HIV positive participants ( $57 \%$ vs. $43 \%, P=0.046$ ). Multivariate analysis revealed that a negative HIV status $(P=0.017)$ and prior knowledge of contraceptive implants $(P=0.001)$ were independently associated with increased uptake of contraceptive implants.

Conclusion: There was a high uptake of immediate postpartum contraceptive implants among both HIV infected and un-infected women; efforts therefore need to be made in promoting this method of family planning in Kenya and providing this method to women in the immediate postpartum period so as to utilize this critical opportunity to increase uptake and reduce the high unmet need for family planning.

\footnotetext{
* Correspondence: kiborm@u.washington.edu

${ }^{2}$ Department of Global Health, University of Washington, Seattle, WA, USA

Full list of author information is available at the end of the article
} 


\section{Background}

Sub-Saharan Africa has the highest burden of adult and pediatric HIV infections globally [1]. The Government of Kenya in collaboration with local and international donors and organizations has made concerted efforts in the prevention, care and treatment of HIV/AIDS with some success. However, HIV prevalence in Kenya is still unacceptably high with a prevalence of $5.6 \%$ among adults with women more likely to be infected (6.9\%) than men (4.4\%) [2]. The prevalence is even higher among pregnant women and stands at $9 \%$ [3]. The second prong of the World Health Organization/United Nations (WHO/UN) strategy on prevention of mother to child HIV transmission (PMTCT) is prevention of unintended pregnancy among HIV infected women [4]. Although family planning is a proven cost effective strategy for achieving Millennium development goals (MDGs) and PMTCT goals and for reducing maternal and childhood morbidity and mortality [4], the rate of unintended pregnancy ( $26 \%$ for mistimed and $17 \%$ for unwanted pregnancy), and unmet needs of family planning (FP) (25\%) in Kenya still remains high $[3,5]$.

Contraceptive implants are known to be safe and effective even in the immediate postpartum period, but their use in Kenya remains low (only $1.3 \%$ of the general population currently use it) [4] and its use at the immediate postpartum period is almost negligible.

The study aim was to determine and compare uptake and factors influencing uptake of immediate postpartum contraceptive implant among HIV infected and uninfected women. The findings of this study will assist in identifying acceptability of immediate postpartum contraceptive implant and this in turn has the potential to lead to policy change regarding availability and provision of postpartum implants in our health institutions, thus contributing to reducing the high unmet need of FP and potentially achieve the second prong of PMTCT.

\section{Methods}

\section{Study design and setting}

We conducted a cross sectional study targeting HIV infected and uninfected postpartum women admitted to the postnatal wards (PNW) of two Kenyan district hospitals, Naivasha District Hospital (a rural hospital) and Mbagathi District Hospital (an urban hospital) from the months of July to October 2012. Naivasha and Mbagathi district hospitals are public hospitals that provide both general and specialized care including regular FP service. A room within the postnatal units was used to provide FP counseling and insertion of implants to those who consented.

\section{Study population}

Study participants were postpartum mothers in the postnatal wards of the two hospitals after delivery and before discharge. One HIV positive mother was recruited for every one HIV negative mother. The HIV status was obtained from the patients' ANC card during admission into the postnatal wards and then confirmed from the patients' hospital files. Those with unknown HIV status, were tested in the maternity unit and results documented in the patients' files. The enrollment criteria included; consenting adult postpartum women with known HIV status, normotensive and with no known serious medical conditions such as active liver disease, deep venous thrombosis, migraine with aura, renal failure or breast cancer.

\section{Ethical considerations}

Ethical approval was obtained from the Kenyatta National Hospital/University of Nairobi (KNH/UON) Ethics and Research committee. Consent was obtained in writing from all the study participants after adequate explanation for enrollment in this study. The study was conducted using an anonymous survey with no name identifying information provided in the questionnaire. All measures to maintain anonymity and confidentiality were strictly followed.

\section{Data collection and recruitment}

Participant enrollment into the study was carried out by convenience sampling based the admission of patients in the PNW until the numbers of HIV positive and negative balanced. Pretesting of the questionnaire was done at the study sites using the same protocol and no revision was required. Trained research nurses administered the structured questionnaire and the information collected included; socio-demographic characteristics, parity, contraceptive knowledge and use, spouse approval of contraceptive use, future fertility intentions and knowledge and opinions about contraceptive implants. This was then followed by standardized contraceptive counseling about all available FP methods and specifically on the study method (implants). Those who further consented to insertion of contraceptive implants were inserted immediately after signing part $B$ of the consent form and were encouraged to continue using barrier methods. A card that indicated the method given, date inserted and expiry date was given together with post insertion instructions on wound care. They were then advised to go to FP clinic of their choice for follow up. Those who did not consent to implant insertion were counseled on importance of FP use and referred to FP clinics of their choice for routine postpartum care (Fig. 1).

\section{Data analysis}

Descriptive statistics were used to describe baseline maternal characteristics such as age, parity, education levels and FP knowledge. Mean and median was used for continuous variables and frequencies, and proportions were 


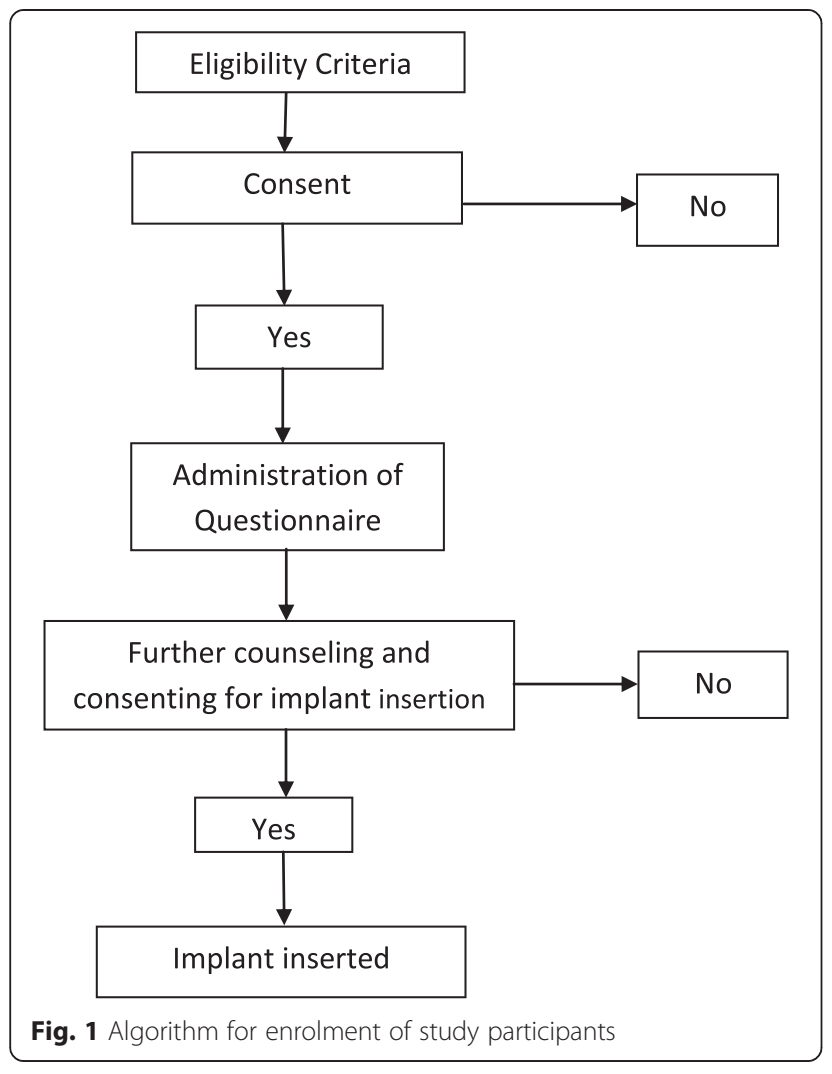

used for categorical variables. T-test was applied to compare means, while a two-sided chi-square test was used to compare proportions between the two groups. Fisher's exact test was also utilized when at least one cell had a value of zero. Logistic regression was then applied to test the strength of association between demographic and reproductive variables and the primary outcome - uptake of contraceptive implants. The significant factors were then subjected to multivariate analysis to analyse for independent association.

The data was entered into password protected Microsoft Access Database and subsequently transferred to SPSS statistical package for analysis. SPSS 16.0, Inc., 2007.

\section{Study limitations}

One of the study limitations was selection bias, due to the non-probability sampling method but this was mitigated by the large sample size.

\section{Results}

\section{Socio-demographic characteristics}

185 participants were enrolled - 91 HIV positive and 94 HIV negative. The socio-demographic profiles of the HIV positive and negative participants were similar (Table 1). Majority of the participants were in their midtwenties and married, while close to half had completed primary education and were employed.
Table 1 Socio-demographic characteristics of participants by HIV status

\begin{tabular}{|c|c|c|c|}
\hline \multirow[t]{2}{*}{ Variable } & \multicolumn{2}{|l|}{ HIV Status } & \multirow[t]{2}{*}{$P$ value } \\
\hline & $\begin{array}{l}\text { HIV Positive }(n=91) \\
N(\%)\end{array}$ & $\begin{array}{l}\text { HIV Negative }(n=94) \\
N(\%)\end{array}$ & \\
\hline \multicolumn{4}{|l|}{ Age } \\
\hline $\begin{array}{l}\text { Average age } \\
\text { (years) } \pm S D\end{array}$ & $27.5 \pm 5.4$ & $24.5 \pm 5.2$ & $<0.001$ \\
\hline \multicolumn{4}{|l|}{ Study site } \\
\hline Naivasha D.H & $47(51)$ & $46(49)$ & 0.71 \\
\hline Mbagathi D.H & $44(48)$ & $48(52)$ & \\
\hline \multicolumn{4}{|l|}{ Formal education } \\
\hline Primary & $50(48.5)$ & $53(51.5)$ & 0.84 \\
\hline Secondary/tertiary & $41(50)$ & $41(50)$ & \\
\hline \multicolumn{4}{|l|}{ Marital status } \\
\hline Married & $71(46.1)$ & $83(53.9)$ & 0.06 \\
\hline Not married & $20(64.5)$ & $11(35.5)$ & \\
\hline \multicolumn{4}{|l|}{ Occupation } \\
\hline Employed & $45(48)$ & $48(52)$ & 0.83 \\
\hline Not employed & $46(50)$ & $46(50)$ & \\
\hline
\end{tabular}

\section{Reproductive characteristics}

Majority of the participants had attended ANC (96\%), however HIV positive mothers were significantly more likely to have had a discussion with a health care worker at the ANC than their HIV negative counterparts $(\mathrm{P}=0.002)$, [Table 2]. HIV positive mothers regarded the ideal family size as having fewer children compared to HIV negative

Table 2 Reproductive health characteristics of participants by HIV status

\begin{tabular}{|c|c|c|c|c|}
\hline \multirow[t]{2}{*}{ Variable } & \multicolumn{2}{|l|}{ HIV status } & \multirow{2}{*}{$\begin{array}{l}\text { Total } \\
\text { N (\%) }\end{array}$} & \multirow{2}{*}{$\begin{array}{l}P \\
\text { value }\end{array}$} \\
\hline & $\begin{array}{l}\text { HIV+ }(n=91) \\
N(\%)\end{array}$ & $\begin{array}{l}\text { HIV - }(n=94) \\
N(\%)\end{array}$ & & \\
\hline \multicolumn{5}{|l|}{ ANC attendance } \\
\hline Yes & $87(48.9)$ & $91(51.1)$ & $178(96.2)$ & 0.482 \\
\hline No & $4(57.1)$ & $3(42.9)$ & $7(3.8)$ & \\
\hline \multicolumn{5}{|c|}{ FP discussion during ANC } \\
\hline Yes & $64(58.2)$ & $46(41.8)$ & $110(59.5)$ & 0.002 \\
\hline No & $27(36)$ & $48(64)$ & $75(40.5)$ & \\
\hline $\begin{array}{l}\text { Ideal family size, } \\
\text { Mean (SD) }\end{array}$ & $2.9(0.8)$ & $3.3(0.9)$ & $3.1(0.9)$ & 0.007 \\
\hline \multicolumn{5}{|c|}{ Number of pregnancies } \\
\hline Gravida 1 & $16(29.1)$ & 39 (70.9) & $55(30)$ & $<0.001$ \\
\hline Gravida 2 & $29(53.7)$ & $25(46.3)$ & $54(29)$ & 0.44 \\
\hline $\begin{array}{l}\text { Gravida } 3 \text { and } \\
\text { above }\end{array}$ & $46(59)$ & $30(41)$ & $76(41)$ & \\
\hline \multicolumn{5}{|c|}{ Choice of pregnancy } \\
\hline Planned & $43(47)$ & $60(64)$ & $103(56)$ & 0.024 \\
\hline Unintended & $48(53)$ & $34(36)$ & $82(44)$ & \\
\hline
\end{tabular}


mothers, however they were more likely to report higher order pregnancies. There was also a high overall rate of unintended pregnancy of $44 \%$ among all participants and this was significantly higher in HIV positive (53\%) compared to HIV negative (36 \%) mothers $(\mathrm{P}=0.024)$, [Table 2].

\section{Contraceptive knowledge}

Most participants were aware about modern methods of FP with injectable contraceptives $(93 \%)$ and contraceptive pills (92\%) being the most commonly known FP methods, followed by IUCD (65\%), male condom (62\%) and implants (61\%) as shown in Table 3. Natural FP methods such as Lactational Amenorrhoea (LAM) (3\%) and rhythm methods $(2.7 \%)$ were among the least known FP methods. Only about a quarter of all participants knew about female sterilisation (29\%). Significantly more HIV positive women knew about sterilization methods than HIV negative women [Table 3].

\section{Uptake of contraceptive implant}

The overall uptake of immediate postpartum contraceptive implants was $50.3 \%$ [Table 4], however HIV positive mothers were less likely to accept implant insertion than their HIV negative counterparts (OR 0.91 [95 \% CI: 0.82-0.998], $\mathrm{P}=0.046$ ). Table 4 also describes the uptake of implants by HIV status, whereby $43 \%$ and $57 \%$ of HIV positive and negative mothers respectively accepted immediate postpartum implants insertion.

\section{Factors influencing uptake}

As demonstrated in Table 5, the uptake of immediate postpartum implants was higher in postpartum mothers who were from Mbagathi District Hospital and unemployed; however none of these associations were statistically significant. Interestingly, mothers' education level or marital status did not influence implants uptake.

Table 3 Knowledge of FP methods among HIV positive and negative women

\begin{tabular}{|c|c|c|c|c|}
\hline \multirow{2}{*}{$\begin{array}{l}\text { Knowledge of } \\
\text { FP methods }\end{array}$} & \multicolumn{2}{|l|}{ HIV status } & \multirow{2}{*}{$\begin{array}{l}\text { Total } \\
\text { N (\%) }\end{array}$} & \multirow{2}{*}{$\begin{array}{l}P \\
\text { value }\end{array}$} \\
\hline & Positive N (\%) & Negative N (\%) & & \\
\hline IUCD & $65(71.4)$ & $55(58.5)$ & $120(65)$ & 0.066 \\
\hline LAM & $2(2.2)$ & $4(4.3)$ & $6(3.2)$ & 0.430 \\
\hline Rhythm method & $2(2.2)$ & $3(3.2)$ & $5(2.7)$ & 0.677 \\
\hline Female condom & $11(12)$ & $18(19.1)$ & $29(15.7)$ & 0.187 \\
\hline Female sterilization & $39(42.9)$ & $15(16)$ & $54(29.2)$ & $<0.001$ \\
\hline Implants & $62(68.1)$ & $51(54.3)$ & $113(61.1)$ & 0.053 \\
\hline Injectable & $84(92.3)$ & 88 (93.6) & $172(93)$ & 0.728 \\
\hline Male condom & $64(70.3)$ & $50(53.2)$ & $114(61.6)$ & 0.017 \\
\hline Male sterilization & $11(12.1)$ & $3(3.2)$ & $14(7.6)$ & 0.022 \\
\hline Contraceptive pills & $85(93.4)$ & $85(90.4)$ & $170(92)$ & 0.458 \\
\hline Withdrawal method & $16(17.6)$ & $13(13.8)$ & $29(15.7)$ & 0.483 \\
\hline
\end{tabular}

Table 4 Uptake of immediate postpartum contraceptive implants among HIV infected and Uninfected women at Mbagathi and Naivasha District Hospitals

\begin{tabular}{lllll}
\hline Variable & \multicolumn{2}{l}{$\begin{array}{l}\text { Postpartum contraceptive } \\
\text { implants uptake }\end{array}$} & OR [95 \% Cl] & P value \\
\cline { 2 - 3 } & Yes & No & & \\
\hline Overall uptake & $93(50.3 \%)$ & $92(49.7 \%)$ & & \\
HIV status & & & & \\
Positive & $39(42.9 \%)$ & $52(57.1 \%)$ & $0.91[0.82-0.99]$ & 0.046 \\
Negative & $54(57.4 \%)$ & $40(42.6 \%)$ & Ref & \\
\hline
\end{tabular}

HIV status influenced uptake of postpartum implants with fewer HIV positive mothers accepting implants insertion compared to HIV negative with a trend towards significance, (OR 0.6 [95 \% CI: 0.3-1.0], P = 0.047). Similarly, those with spouse approval were twice as likely to accept postpartum implants than those without spouse approval (OR 2.0 [95 \% CI:1.1-2.4], P = 0.02), while those with prior knowledge of contraceptive implants were three times more likely to accept implants insertion compared to those who had no prior knowledge of implants (OR 3.3 [95 \% CI:1.5-7.4], P = 0.001). Similarly, those of younger age at first pregnancy (19.5 years) were also more likely to accept postpartum implants compared to those of older age at first pregnancy (20.6 years) $(\mathrm{P}$ value $=0.01)$. On multivariate analysis, independent factors found to be associated with increased uptake of implants were; negative HIV status and prior implant knowledge. Younger age at first pregnancy and having spouse approval were not independently associated with uptake of postpartum implants.

On subgroup analysis by HIV status and factors influencing uptake of implant, none of the socio-demographic factors significantly influenced uptake. However, on multivariate analysis, independent factors found to be associated with increased uptake of implants among HIV positive mothers were spouse approval and resumption of sexual activity. Spouse approval was positively associated with increased uptake of postpartum implants; while plans for early resumption of sexual activity were negatively associated with the uptake. On the other hand, in HIV negative mothers, those with prior knowledge of implants were threefold more likely to accept postpartum implants than those without prior knowledge. Early age at first pregnancy was not significantly associated with increased uptake.

\section{Reasons for declining uptake}

Among all clients, the most common reason for declining postpartum implants was "I have to think about it" (30\%) followed by "I have to discuss with my spouse" (24\%) and "I would like to use another method" (23\%). Some had no reason $(11 \%)$ while $12 \%$ were afraid of side effects [Fig. 2]. 
Table 5 Factors influencing uptake of implants among all participants

\begin{tabular}{|c|c|c|c|c|}
\hline \multirow[t]{2}{*}{ Variable } & \multicolumn{2}{|l|}{ Implants uptake } & \multirow[t]{2}{*}{ OR $[95 \% \mathrm{Cl}]$} & \multirow{2}{*}{$\begin{array}{l}P \\
\text { value }\end{array}$} \\
\hline & Yes $(n=93) N(\%)$ & No $(n=92) N(\%)$ & & \\
\hline Average age $\pm S D$ & $25.7 \pm 5.7$ & $26.4 \pm 5.2$ & NA & 0.33 \\
\hline \multicolumn{5}{|l|}{ Study Site } \\
\hline Naivasha D.H & $43(46.2)$ & $50(53.8)$ & $0.7[0.4-1.3]$ & 0.27 \\
\hline Mbagathi D.H & $50(54.3)$ & $42(45.7)$ & 1.0 & \\
\hline \multicolumn{5}{|l|}{ Formal education } \\
\hline Primary & $53(51.5)$ & $50(48.5)$ & $1.1[0.6-2.1]$ & 0.72 \\
\hline Secondary/tertiary & $40(48.8)$ & $42(51.2)$ & 1.0 & \\
\hline \multicolumn{5}{|l|}{ Marital status } \\
\hline Married & 78 (50.6) & $76(49.4)$ & $1.1[0.5-2.6]$ & 0.82 \\
\hline Not married & $15(48.4)$ & $16(51.6)$ & 1.0 & \\
\hline \multicolumn{5}{|l|}{ Occupation } \\
\hline Employed & $43(46.2)$ & $50(53.8)$ & $0.7[0.4-1.3]$ & 0.270 \\
\hline Unemployed & $50(54.3)$ & $42(45.7)$ & 1.0 & \\
\hline \multicolumn{5}{|l|}{ HIV status } \\
\hline Positive & 39 (42.9) & $52(57.1)$ & $0.6[0.3-1.0]$ & 0.047 \\
\hline Negative & $54(57.4)$ & $40(42.6)$ & 1.0 & \\
\hline \multicolumn{5}{|l|}{ Choice of pregnancy } \\
\hline Planned pregnancy & $53(51)$ & $50(49)$ & $1.1[0.6-1.9]$ & 0.72 \\
\hline Unintended pregnancy & $40(49)$ & $42(51)$ & 1.0 & \\
\hline Ideal family size (Mean \pm SD) & $3.05 \pm 0.8$ & $3.12 \pm 0.9$ & NA & 0.61 \\
\hline \multicolumn{5}{|l|}{ Male birth } \\
\hline Yes & $44(48.9)$ & $46(51.1)$ & $0.8[0.4-1.5]$ & 0.44 \\
\hline No & $47(54.7)$ & $39(45.3)$ & 1.0 & \\
\hline \multicolumn{5}{|l|}{ Gravida } \\
\hline Gravida 1-2 & $56(51.4)$ & $53(48.6)$ & $1.1[0.6-2.1]$ & 0.72 \\
\hline Gravida 3 and above & $37(48.7)$ & $39(51.3)$ & 1.0 & \\
\hline \multicolumn{5}{|l|}{ Spouse approval } \\
\hline Yes & $73(54.5)$ & $61(45.5)$ & $2.0[1.1-2.4]$ & 0.02 \\
\hline No & $11(55)$ & $9(45)$ & 1.0 & \\
\hline \multicolumn{5}{|l|}{ Jadelle knowledge } \\
\hline Yes & $80(57.1)$ & $60(42.9)$ & $3.3[1.5-7.4]$ & 0.001 \\
\hline No & $13(28.9)$ & $32(71.1)$ & 1.0 & \\
\hline \multicolumn{5}{|l|}{ Age at first pregnancy } \\
\hline Mean \pm SD & $19.5 \pm 2.7$ & $20.6 \pm 3.7$ & NA & 0.013 \\
\hline \multicolumn{5}{|l|}{ Plans for resumption to sexual } \\
\hline Activity in weeks (Mean \pm SD) & $11.75 \pm 9.8$ & $9.7 \pm 7.10$ & NA & 0.156 \\
\hline
\end{tabular}

However, there were twice as many HIV negative women compared to HIV positive women who wanted to discuss contraceptive implant uptake with their spouse. On the other hand as shown in Fig. 3, HIV positive mothers were five times more likely than HIV negative to report being afraid of side effects and three times more likely to report that they wished to use another method. The difference in the reasons given for declining postpartum implants between the two groups were statistically significant $(\mathrm{P}=0.039)$. There were similar proportions of HIV positive and negative clients who declined postpartum implants because they had to think about it (15\%) or had no reason of declining (5\%). 


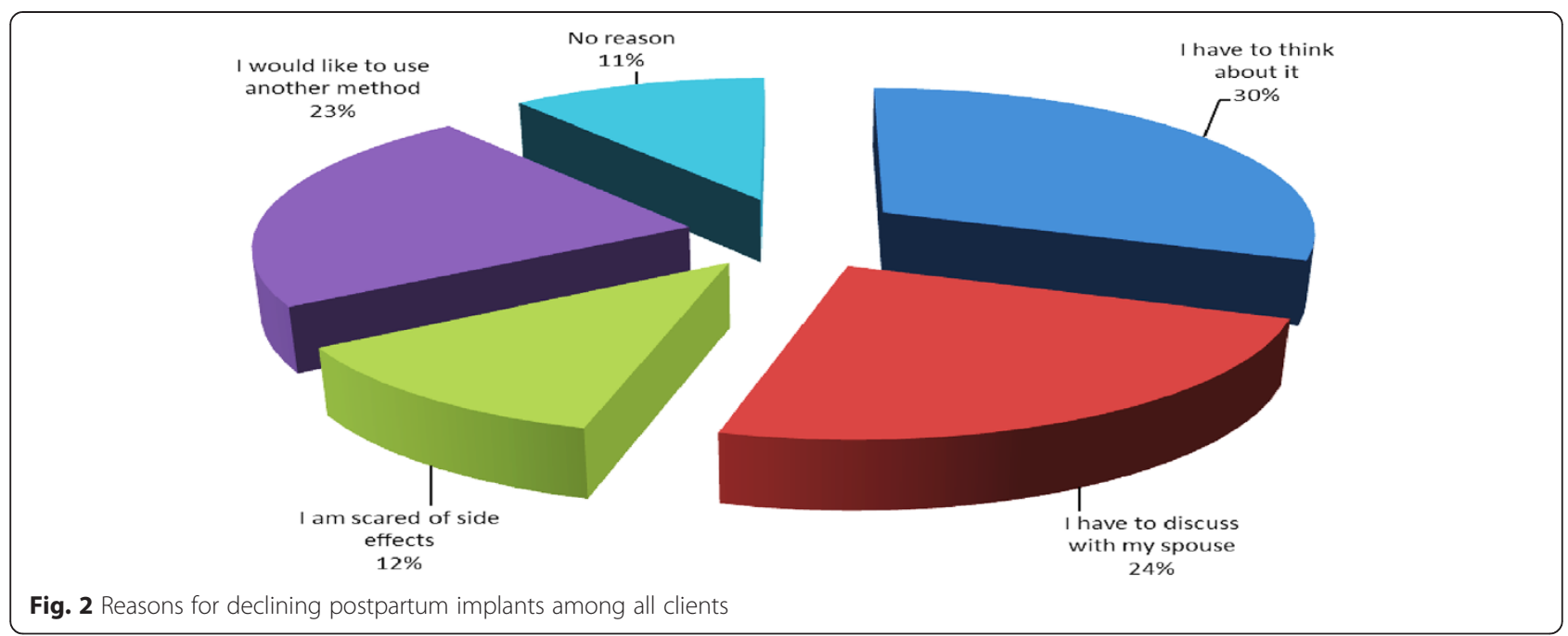

\section{Discussion}

In this study we demonstrated a good uptake of postpartum implants at $50.3 \%$, with the uptake being higher among the HIV negative (57 \%) than the HIV positive clients (43\%). Although we demonstrated an uptake higher than that found by Dhont et al. in Rwanda (38 \%) [6] - who looked at effect of improved access on the uptake of Long Acting Reversible Contraceptives (LARC)both studies show that improving access to LARC improves their uptake particularly in regards to implants. The uptake in our study is much higher than the current use of contraceptive implants in Kenya where only $1.3 \%$ of the general population is currently using it [5]. Currently, immediate postpartum contraceptive implants are not routinely offered in the postnatal wards of our health care system and are not part of the national FP guideline [7]. Despite proven safety in the use of immediate postpartum contraceptive implants, [8] the Kenya national guidelines on FP which are based on the WHO medical eligibility criteria (MEC), [9] have restricted its use in breastfeeding mothers to 4 weeks postpartum and allowed for its immediate postpartum use only in non- breastfeeding mothers [7]. In view of the high uptake we found when we offered contraceptive implants immediately postpartum, there is need to change this policy so as to improve access to this contraceptive method among both HIV positive and negative women. This will go a long way in reducing the unmet need of FP, high rate of unintended pregnancies and mother to child transmission of HIV. Hopefully the new WHO MEC expected this year will have these changes.

Prior knowledge of implants positively influenced uptake among all participants with those who knew about implants being three times more likely to accept them. This finding is consistent with that of Tanfer who found that interest in the use of implants increased with its knowledge [10]. Similarly, Jacobstein and Stanley attributed the upswing of use of contraceptive implants in Eastern and South African countries in particular Ethiopia and Rwanda to the marked rise in implants knowledge [11]. Educating the public on this method will result in a ripple effect of improving uptake, reducing unintended pregnancies and PMTCT.

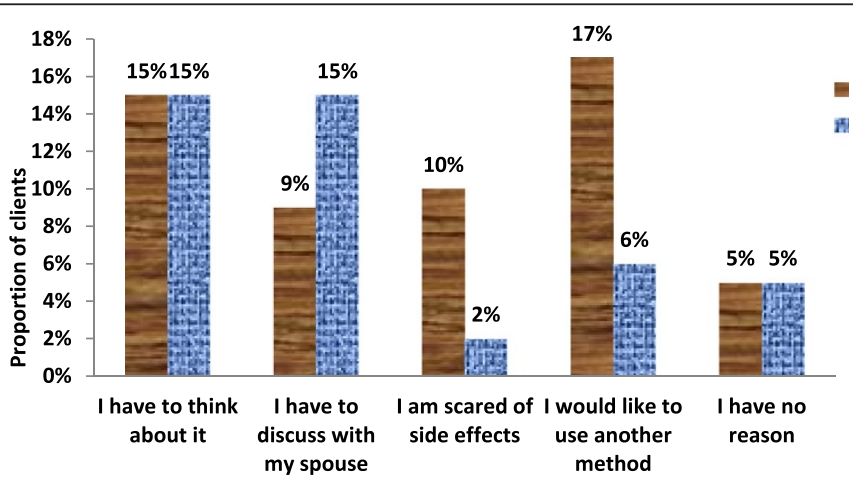

Fig. 3 Reasons for declining postpartum implants by HIV status, P value $=0.039$ 
On the other hand, spouse approval significantly influenced uptake among all participants and especially among HIV positive clients. Similar findings were found by Bii et al. [12] and Akelo et al. [13], who found that partner involvement and approval was crucial in FP decision making in HIV positive mothers. Mutiso et al. also found that marital status and having a regular sexual partner influenced contraceptive use [14]. This finding emphasizes the importance of individual and couple FP counseling to improve FP uptake and hence achieve PMTCT.

The findings of this study on the factors that influence uptake of contraceptive implants, concur with the argument of Johnson et al. [15] that HIV positive women exhibit fertility desires and contraceptive behavior that are different from other women, and therefore, more needs to be done to understand their specific needs and concerns in order to reduce the unacceptably high rate of unintended pregnancy and achieve the second prong of PMTCT. As demonstrated in this study, different factors influenced uptake of immediate postpartum implants differently among HIV positive and negative mothers. In addition the HIV positive women were more concerned about the potential side effects of implants; this is consistent with the findings of Credé et al. who also found that HIV positive women were concerned of the safety of hormonal FP methods given their health status [16]. Therefore, more needs to be done to understand these factors that influence FP uptake among both HIV positive and negative mothers so that appropriate strategies are put in place to reduce unmet needs of FP.

The main reason for declining to implants insertion among all clients was; wanted to think about it, need to discuss with spouse and wanted to use another method, but among HIV positive clients there was also the fear of side effects. In view of this, proper education on implants as an FP method and its effect on HIV as well as emphasis on spouse involvement needs to be given to this subgroup in order to allay any fears and improve its acceptance.

Consistent with the findings of Peltzer et al. [17] who looked at FP needs of PMTCT clients in resource poor settings in South Africa, we also found high fertility desire among HIV positive clients where more than a half of HIV infected women $(67 \%)$ regarded three or more children as ideal family. Similarly, more than a half of HIV positive clients reported higher order pregnancies of 3 and above compared to their HIV negative counterparts. This is not surprising considering they were significantly older than the HIV negative women in the study. This may also explain the 'replacement phenomenon' described by Magadi and Agwanda in which HIV positive women tend to get pregnant more frequently so as to replace any child loss resulting from the anticipated increased infant/ child mortality [18].
Prong 2 of PMTCT is elimination of unintended pregnancy. This study found an overall rate of unintended pregnancy of $44 \%$, and $60 \%$ among the HIV positive clients in comparison to Kenya Demographic and Health Survey (KDHS) 2009 that reported an unintended pregnancy rate of $26 \%$. This finding is consistent with other studies which have shown that HIV positive women are more likely to report higher rates of unintended pregnancies [17-19]. This can be explained by the fact that HIV positive women regarded 1-2 children as ideal family size yet majority reported their index pregnancy to be of higher order (gravida 3 and above). This study finding has reaffirmed the need for stakeholders to strengthen the 2nd prong of PMTCT.

\section{Conclusion}

The high rates of unintended pregnancies especially among HIV positive women is disturbing and this indicates missed opportunity for PMTCT and hence the need to scale up the second prong of PMTCT.

Postpartum contraceptive implants are an acceptable, effective and safe FP method and should be considered to be offered routinely to both HIV positive and negative postpartum mothers.

Ministry of Health through the Division of Reproductive Health need to develop policies and review FP guidelines to allow use of implants in the postpartum period so as to increase its uptake in tandem with its strategic plan on long acting and reversible contraceptive methods.

There is a need to develop communication and advocacy strategies to increase public awareness of this method to improve uptake. Integration of FP services to HIV care and other reproductive health services will improve access and should also emphasize on partner participation in decision making. Concerns among HIV positive women of potential side effects are valid and health education strategies need to be developed to allay fears and improve understanding of this method of FP.

\section{Competing interests}

The authors declare that they have no competing interests.

\section{Authors' contributions}

MMS was involved in conception and design, acquisition of data, data analysis and interpretation, drafting the manuscript and manuscript revision. JGK participated in conception and design, data interpretation and manuscript revision. FO was involved in conception and design, data analysis and interpretation. RK was involved in conception and design, data interpretation and manuscript revision. MWK was involved in conception and design, data interpretation, drafting the manuscript and manuscript revision. JNK was involved in conception and design, manuscript drafting and revision. JK participated in conception and design, data analysis and interpretation, drafting the manuscript and manuscript revision. All authors read and approved the final manuscript.

\section{Acknowledgements}

The funding of this study is from the Linked award -Strengthening Maternal, Newborn and Child Health (MNCH) Research Training in Kenya. The grant is linked to Partnership for Innovative Medical Education in Kenya (PRIME-K). 
The project was supported by Award Number 5R24TW008907 from the US National Institutes of Health. The content is solely the responsibility of the authors and does not necessarily represent the official views of the US National Institutes of Health.

My gratitude goes to staff and management of Mbagathi and Naivasha District hospitals for allowing me to conduct the study in their institutions. A special thank you goes to the mothers who participated in the study.

\section{Author details}

'Department of Obstetrics and Gynecology, University of Nairobi, Nairobi, Kenya. ${ }^{2}$ Department of Global Health, University of Washington, Seattle, WA, USA. ${ }^{3}$ Department of Obstetrics and Gynaecology, Kenyatta National Hospital, Nairobi, Kenya.

Received: 20 January 2015 Accepted: 12 August 2015

Published online: 19 August 2015

\section{References}

1. Technical Consultation on elimination of Mother to Child Transmission. Final meeting report. Towards the elimination of Mother to Child transmission of HIV. Geneva: WHO; 2011. http://www.who.int/hiv/pub/mtct/ elimination_report/en/.

2. Kenya Aids Indicator Survey Report 2012. National AIDS and STI Control Programme, Ministry of Health, 2013. www.nacc.or.ke/images/documents/ KAIS-2012.

3. Kenya Aids Indicator Survey Final Report 2009. National AIDS and STI Control Programme. www.aidskenya.org.

4. Scaling up prevention of Mother to Child Transmission of HIV, A report of the CSIS Global Health Policy Centre, Washington DC. Margaret Reeves, (2011), http://csis.org/publication/scaling-prevention-mother-child-transmission-hiv.

5. Kenya Demographic Health Survey, KDHS. Kenya National Bureau of Statistics (KNBS) and ICF Macro. Kenya demographic and health survey. 2008;2008-2009:2010. Available at: http://apps.who.int/medicinedocs/ documents/s17116e/s17116e.pdf.

6. Dhont N, Ndayisaba GF, Peltier CA, Nzabonimpa A, Temmerman M, Van de Wijgert J. Improved access increases postpartum uptake of contraceptive implants among HIV-positive women in Rwanda. Eur J Contracept Reprod Health Care. 2009;14(6):420-5.

7. National Family Planning Guidelines for service providers. Division of Reproductive Health, Ministry of Public Health and Sanitation. Kenya: Nairobi; 2010.

8. Nathalie K, Kathryn C, Kavita N. Progestogen-only contraceptive use among breastfeeding women: a systematic review. A Review Article, Contraception. 2010:82:17-37.

9. World Health Organization Medical Eligibility Criteria for Contraceptive use. 4th edition 2009. Geneva: WHO; 2009. Available at: http://www.spdc.pt/files/ publicacoes/5_11292_2.pdf. ISBN 9789241563888.

10. Tanfer K. Knowledge, attitudes and intentions of American women regarding the hormonal implant. Fam Plann Perspect. 1994;26(2):60-5.

11. Roy J, Harriet S. Contraceptive implants: providing better choice to meet growing family planning demand. Global Health: Science and Practice. 2013;1:1.

12. Bii SC, Otieno-Nyunya B, Siika A, Rotich JK. Family Planning and safer sex practice among HIV infected women receiving Prevention of Mother to Child Transmission services at Kitale District Hospital. East Afr Med Journal. 2008:85(1):46-50.

13. Victor A, Sonali G, Borkow CB. Attitudes toward Family Planning among HIV-Positive Pregnant Women Enrolled in a Prevention of Mother-To-Child Transmission Study in Kisumu, Kenya. PLoS One. 2013;8:8.

14. Mutiso SM, Kinuthia J, Qureshi Z. Contraceptive use among HIV infected women attending Comprehensive Care Centre. East Afr Med J. 2008:85:171-7.

15. Johnson KB, Akwara P, Rutstein SO. Fertility preferences and the need for contraception among women living with HIV: the basis for a joint action agenda. AIDS. 2009;23 Suppl 1:S7-S17.

16. Credé S, Hoke T, Constant D, Green MS, Moodley J, Harries J. Factors impacting knowledge and use of long acting and permanent contraceptive methods by postpartum HIV positive and negative women in Cape Town, South Africa: a cross-sectional study. BMC Public Health. 2012;12:197.

17. Peltzer K, Chao LW, Dana P. Family planning needs among HIV positive and negative prevention of mother to child transmission (PMTCT) clients in a resource poor setting in South Africa. AIDS Behaviour H Journal. 2009;13(5):973-9. Epub 2008 Feb 20. KPeltzer@hsrc.ac.za.

18. Magadi MA, Agwanda AO. Investigating the association between HIV/AIDS and recent fertility patterns in Kenya. Soc Sci Med. 2010;71(2):335-44. doi:10.1016/j.socscimed.2010.03.040. Epub 2010 Apr 24.

19. Nattabi B, Li J, Thompson SC, Orach CG, Earnest J. Family planning among people living with HIV in post-conflict Northern Uganda: A mixed methods study. Confl Health 5: 18. doi: 10.1186/1752-1505-5-18.

\section{Submit your next manuscript to BioMed Central and take full advantage of:}

- Convenient online submission

- Thorough peer review

- No space constraints or color figure charges

- Immediate publication on acceptance

- Inclusion in PubMed, CAS, Scopus and Google Scholar

- Research which is freely available for redistribution 